\title{
Awareness and Attitude of Nurses in Regard to Providing Hospice Care
}

\author{
Alireza Mohajjel Aghdam, Mir Hossein Aghaei*, Hadi Hassankhani, Azad \\ Rahmani
}

\begin{abstract}
Background: Awareness and attitudes of nurses regarding end of life care are important factors in providing hospice care. In an extensive literature review, we found no related articles investigating Iranian nurses awareness and attitudes about providing such care. Objectives: The aims of this study were to investigate the awareness and attitudes of Iranian nurses in providing hospice care. Materials and Methods: In this descriptive-correlational study, 240 nurses employed in six educational centers were selected by non-randomized stratified sampling. The data collection instruments included an awareness test and attitudes regarding providing end of life care in hospice questionnaire. The data were analyzed using descriptive statistics and independent sample t-tests, one-way ANOVA, and Pearson correlation tests. Results: The nurses' awareness score was 14.3 out of 29 and $55.7 \%$ of them stated that they had not received any education in providing end of life care. Also, by obtaining the score of 91.7 out of 120 the attitudes of participants in providing end of life care in hospices were positive. In addition, the highest attitudes score of nurses were in the dimensions of benefits of implementation and health care team. Conclusions: Considering low awareness of nurses about end of life care in hospices, continuing education should be provided for them in this regard. Especially, by considering the positive attitude of nurses, providing such programs could help develop hospice care in Iran.
\end{abstract}

Keywords: End life care - hospice - awareness - attitude - Iran

Asian Pac J Cancer Prev, 16 (16), 6941-6945

\section{Introduction}

Chronic diseases are the most important health and social problems in today's societies (Baghaei et al., 2008). Many patients who suffer from these diseases, cancer especially, are at the end of their life (Dunn et al., 2005) and have many physical, psychological, social, and spiritual needs (Khan et al., 2008; Kirchhoff et al., 2012 ; Park et al., 2012; Ezat et al., 2014). So, attention to these patients and their family members is important. Despite the development of advanced high-technology treatments still the main treatment for these patients is improving their quality of life at the end stages of life. In many cases, these patients are kept on hospital bed for a long time without effective care, or they were given to their families to take care of them. Unfortunately, in many cases, caregivers do not have the knowledge and skills needed for proper care of these patients (Magantoa et al., 2004; Hauptman et al., 2005).

Nowadays, the main approach for providing care for end of life patients in developed countries is hospice care. Hospice is a model of end of life care in that the patients and their family members are supported by trained health care providers (National Hospice Foundation, 2012). Theses cares are not aimed to increase the lifelong, but are based on increasing quality of life of patients and their caregivers in the late stages of disease (World Health Organization, 2002; Alexandria, 2013). This model of care is focused on the control of symptoms and needs of patient and supports patients and their families psychologically (National Hospice Foundation, 2012; Azami et al., 2015; National Hospice and Palliative Care Organisation, 2010). The history of hospice program in the world goes back for about 45 years ago and 885,000 patients have used this service in the United States in 2002. Also, 90\% of patients with end stages of cancer are requesting to use these services (Catherine et al., 2010; Csikos et al., 2010).

One of the important principles for providing end of life care is sufficient numbers of trained health personnel (Carol et al., 2008). Among them, nurses due to the nature of their profession had an important role. Nurses have more contact with these patients and their families and are responsible for providing main end of life cares (Fink et al., 2010). So, the nurses should always try to acquire specific end of life skills and should have a positive attitude towards these patients and addressing their problems. Therefore, it is recommended that nurses who taking care of these patients should receive the proper training about end of life care and how to communicate effectively with these patients and their family members 
(Carol et al., 2008). There are no established programs for end of life cares especially in the form of hospice in Iran. On the other hand, with growing the numbers of end of life patients, the need for providing these services will be increase in Iran.

The aims of this study were to investigate the Awareness and attitude of nurses in providing hospice cares.

\section{Materials and Methods}

This is a descriptive - correlational study in which 240 employed nurses participated in the six educational centers affiliated to Tabriz University of Medical Sciences, Iran. Inclusion criteria included: working in one of the mentioned educational centers, having at least one year of job experience, and willingness to participate in the study. After a pilot study on 30 nurses, the sample size was estimated as 225 nurses. During data collection, 250 nurses were invited to participate in the study with non-random stratified sampling method. Finally, the data of 240 nurses were collected (participation rate $=96 \%$ ).

The data collection was conducted by using a questionnaire designed based on an extensive literature review (Cramer et al., 2003; Stephan et al., 2008; Csikos et al., 2010). This questionnaire was consisted of three main parts. The first part included 11 items that reviewed some demographic and professional characteristics of the nurses. The second part consisted of 7 items that investigated the nurses' awareness regarding hospice care. Two first items in this section had "Yes" and "No" options that were given a score of 2 to "Yes" and a score of 1 to "No" option. Five next items include options from "very low" to "very high" that and scores from 1 to 5 assigned to them, respectively. Therefore, the score in this area was vary from 7 to 29 and a higher score indicates more awareness regarding these services. The third part included 30 items that examined the nurses' attitude about providing end of life and hospice cares in 4 sections including: need (7 items), welcoming and social acceptance (5 items), benefits and effects of implementation ( 10 items), and care team ( 8 items). The answer to each item is beside a fiveitem Likert scale from "strongly disagree" to "strongly agree" which score of 1 to 5 assigned them respectively. So, the score for need, social acceptance, benefits and effects of implementation, and care team were varying from: 7 to 35,5 to 25,10 to 50 , and 8 to 40 , respectively. So, the final score was varying from 30 to 150 . It should be noted that the final score of each section was calculated based on score 100 .

The validity of the questionnaires was approved by a panel of 12 academic staff from Tabriz University Medical
Sciences. To evaluate the reliability of questionnaires a pilot study was conducted by participating 30 nurses. Reliability was determined by using Cronbach's alpha coefficient that was calculated as 0.82 for attitude questionnaire and 0.80 for the awareness questionnaire.

The research project was approved by Regional Ethics Committee at Tabriz University Medical Sciences. In fact, the number of nurses in each educational center was obtained from each centers' nursing office. Based on the number of nurses in each center, the sample size was allocated to that center. Then, the nurses were selected in each center by convenience sampling method. Then, the nurses in different shifts were invited to participate in the study. Brief information about the aim and method of the study was given to all potential participants and informed consent was obtained from all of them. Then, a questionnaire was given to the nurses. After completing the questionnaire, the nurses put them into a closed box in a nursing office.

The data was analyzed using SPSS statistical software (version 13). Descriptive statistics including frequency, percentage, mean, and standard deviation were used to describe the demographic characteristics of participants, their awareness and attitude toward providing palliative care in hospice. Also, independent samples t-test, one-way ANOVA, and Pearson correlation test was performed to investigate the relationships of nurses' demographic characteristics and their awareness and attitude toward providing palliative care in hospice.

\section{Results}

The analysis of nurses' characteristics showed that the mean age of them was 31.63 years $(\mathrm{SD}=5.32$ years). The majority of nurses were female $(83.3 \%)$, married $(65 \%)$, and with provisional employment status $(71.1 \%)$. Work experience of $39 \%, 52.9 \%$, and $9.9 \%$ of nurses was less than 5 years, between 5 to 15 years, and more than 15 years respectively. Also, $57.5 \%$ of nurses were working in the medical-surgical wards, $29.6 \%$ in intensive care wards, and $12.9 \%$ in psychiatric wards. In addition, $92.5 \%$ of participants have a BS degree in nursing.

About $45 \%$ of nurses had a previous experience in care of their end of life family members and $20.8 \%$ had such experiences in residential care facilities. In addition, $25.8 \%$ of participants had no exposure to end of life patients in recent 12 months, and $41.2 \%$ of them were exposed 1 to 3 cases in this period. Also, nurses working in the intensive care units had the most exposure to these patients and $88.7 \%$ of them had taken care of at least one end of life patient in the past 12 months.

Over the $55 \%$ of nurses were not having an adequate

\section{Table 1. The Nurses' Attitude Towards Providing Hospice Care Based on 100}

\begin{tabular}{lc}
\hline Attitude' areas & Mean scores (Standard Deviation) \\
\hline Feeling the need to specialized end of life care & $76.32(13.9)$ \\
Social acceptance and welcome from specialized end of life care & $90.47(15.77)$ \\
The effects and benefits of performing specialized end of life care & $98.29(14.22)$ \\
Forming the team of specialized end of life care & $97.57(14.07)$ \\
Score of total areas & $91.65(10.55)$ \\
\hline
\end{tabular}


Awareness and Attitude of Nurses in Regard to Providing Hospice Care in Iran

Table 2. The Relationship between Some Demographic Characteristics of Nurses with Their Awareness and Attitude Scores in Providing Hospice care

\begin{tabular}{|c|c|c|c|c|c|}
\hline \multirow{2}{*}{\multicolumn{2}{|c|}{$\begin{array}{c}\text { Main variable } \\
\text { Socio-individual variable }\end{array}$}} & \multicolumn{2}{|c|}{ Awareness } & \multicolumn{2}{|c|}{ Attitude } \\
\hline & & \multirow{2}{*}{$\begin{array}{c}\text { Mean } \\
\text { (Standard Deviation) } \\
14.26(4.37) \\
\end{array}$} & \multirow{2}{*}{$\begin{array}{c}\begin{array}{c}\text { Significance } \\
\text { level of test } \\
\text { index }\end{array} \\
\mathrm{p}=0.2\end{array}$} & \multirow{2}{*}{$\begin{array}{c}\text { Mean (Standard } \\
\text { Deviation) }\end{array}$} & \multirow{2}{*}{$\begin{array}{c}\begin{array}{l}\text { Significance } \\
\text { level of test } \\
\text { index }\end{array} \\
p=0.03\end{array}$} \\
\hline \multirow{2}{*}{ Marital status } & Single & & & & \\
\hline & Married & 15.02(4.98) & $\mathrm{t}=-1.2$ & $111.08(13.05)$ & $\mathrm{t}=2.08$ \\
\hline \multirow{2}{*}{ Gender } & Male & $14.62(5.2)$ & $\mathrm{p}=0.84$ & $113.05\left(13.58_{-}\right.$ & $\mathrm{p}=0.09$ \\
\hline & Female & $14.78(4.7)$ & $\mathrm{t}=0.19$ & $109.28(12.41)$ & $t=1.67$ \\
\hline \multirow{3}{*}{ Degrees } & Associated D. & $14.5(5.32)$ & $\mathrm{p}=0.54$ & $100(8.75)$ & $\mathrm{p}=0.14$ \\
\hline & Bachelor D. & $14.76(4.86)$ & $\mathrm{F}=0.71$ & $110(12.86)$ & $\mathrm{F}=1.83$ \\
\hline & Master D. & $15.32(2.91)$ & & $114.08(7.44)$ & \\
\hline \multirow{4}{*}{ Working experience } & 1-5 Years & $14.3(4.18)$ & $\mathrm{p}=0.23$ & $109.45(12.89)$ & $\mathrm{p}=0.88$ \\
\hline & 6-11 Years & $14.85(5.22)$ & $\mathrm{F}=1.39$ & $110.72(11.97)$ & $\mathrm{F}=0.28$ \\
\hline & 11-15 Years & $14.48(5.33)$ & & $110.74(13.92)$ & \\
\hline & $>15$ Years & 13.84(3.98) & & $107.84(14.19)$ & \\
\hline \multirow{3}{*}{ Working area } & Medical-Surgical & $14.69(4.53)$ & $\mathrm{p}=0.55$ & $110.20(13.23)$ & $\mathrm{p}=0.87$ \\
\hline & Intensive care & $15.21(4.66)$ & $\mathrm{F}=0.68$ & 109.37(10.41) & $\mathrm{F}=0.13$ \\
\hline & Psychiatric Nursing & $14.03(6.05)$ & & $110.52(14.95)$ & \\
\hline \multirow{5}{*}{ Type of Employment } & Formal E. & $13.5(4.25)$ & $\mathrm{p}=0.57$ & $107.31(12.36)$ & $\mathrm{p}=0.71$ \\
\hline & Conditional E. & $14.98(4.99)$ & $\mathrm{F}=0.72$ & $110.47(12.66)$ & $\mathrm{F}=0.53$ \\
\hline & Contractual E. & $15.16(4.66)$ & & $111(14.07)$ & \\
\hline & Mandatory Service & $14.55(3.98)$ & & $110.44(13.45)$ & \\
\hline & Other & $16(5.29)$ & & $105.33(8.32)$ & \\
\hline \multirow{2}{*}{ Caring of close relatives } & Yes & $15.52(5.03)$ & $\mathrm{p}=0.02$ & $109.87(13.94)$ & $\mathrm{p}=0.89$ \\
\hline & No & $14.12(4.48)$ & $\mathrm{t}=2.26$ & $110.09(11.55)$ & $\mathrm{t}=-0.13$ \\
\hline \multirow{2}{*}{ Caring in care centers } & Yes & $17.24(5.24)$ & $\mathrm{p}<0.001$ & $107.06(13.9)$ & $\mathrm{p}=0.07$ \\
\hline & No & $14.13(4.45)$ & $t=4.19$ & $110.74(12.28)$ & $\mathrm{t}=-1.81$ \\
\hline \multirow{5}{*}{$\begin{array}{l}\text { Exposure in the past } 12 \\
\text { months }\end{array}$} & None & $13.3(4.22)$ & $\mathrm{p}<0.001$ & $108.74(13.77)$ & $\mathrm{p}=0.38$ \\
\hline & 1-3 Cases & $14.51(4.46)$ & $\mathrm{F}=5.23$ & $111.23(12.73)$ & $\mathrm{F}=1.04$ \\
\hline & 4-7 Cases & $15.71(5.08)$ & & $108.66(12.56)$ & \\
\hline & 8-11 Cases & $12.57(4.19)$ & & $103.29(11.22)$ & \\
\hline & $>12$ Cases & $17.24(4.96)$ & & $111.10(10.78)$ & \\
\hline
\end{tabular}

education in the care end of life patients and close to $65 \%$ of them did not have enough information about hospice care. The results showed that the mean score of awareness of nurses about end of life care in hospice system was $14.26(\mathrm{SD}=4.37)$. In addition, the general score of nurses' attitude in end of life care in hospices and the scores of all four sub-scales are reported in table 1.

Data analysis showed that there is a weak negative statistically significant correlation between awareness and attitude of participants toward hospice care $(\mathrm{r}=-0.21, \mathrm{p}=$ $0.001)$.Also, the results of Pearson correlation test showed that there is no significant correlation between age of participants and awareness $(\mathrm{p}=0.67)$ and attitude $(\mathrm{p}=0.05)$ of participants toward end of life care at hospice. The relationship between some demographic characteristics of participants with their awareness and attitudes regarding providing end of life care in hospice is reported in Table 2 . As evident in this table, awareness about hospice care was higher in nurses with previous experiences with providing care for end of life patients. In addition, the attitude score was higher among married participants. About other variables, there was no significant relationship between the awareness and attitude of participants with other characteristics (Table 2).

\section{Discussion}

The aim of this study was to investigate the awareness and attitude of Iranian nurses about providing hospice care at end of life. According to an extensive literature review there is no previous studies investigated the awareness and attitude of Iranian nurses about provides end of life care in hospice.

The results of this study show that nurses' awareness regarding providing end life care in hospice is weak and even about $65 \%$ of participants did not have enough 
information on this issue. Contrary to this result, Cramer et al. (2003) showed that nurses in the United States have a relatively high knowledge toward hospice service and $40 \%$ of them had received educations about this issue in past 5 years. On the other hand, along with the results of this study, Sharon et al. and David et al. reported that the Awareness and attitudes of nurses about hospice cares is weak. These results are consistent with the study results of present study.

Also, the results of this study showed that the nurses with a previous history of care of end of life patients had more Awareness regarding providing end of life care in hospice. This result is consistent with previous studies (Cramer et al., 2003; Hasheesh et al., 2013). Maybe the exposure of nurses to the end of life patient's increases their need for information in this regard.

The results of this study showed that participants have a positive attitude toward providing hospice care. Csikos et al. (2010) compared the attitude of Hungarian and American physicians about hospice cares and reported that both American and Hungarian physicians have a positive attitude towards providing these services. In addition, positive attitude of nurses in this study is consistent with the results of other similar studies (Cramer et al., 2003; Stephan et al., 2008).

In our study, most of participants believed that the need for hospice care becomes higher in our society day by day and this subject is consistent with the results of other studies (Luminita et al., 2006; Almuzaini et al., 1998). In addition, participants believed that providing hospice care could be efficient and effective for caring of end of life patients. This result is consistent with a result of a previous study in this regard (Cramer et al., 2003; Ogle et al., 2003). Additionally, participants of this study believed that health care providers from different disciplines should be present in the team providing end of life care. This finding is consistent with the finding of previous studies. For example, Torben et al. (2009) expressed that skill full professionals from different medical systems should be involved in providing hospice services. Also, the results of a study by Stephan et al. (2008) showed that family members and friends should be parted of end of life care team.

The results of present study have some implication in establishing end of life care in Iran. Considering the weak awareness of nurses regarding end of life care in hospice, revising nursing education curriculum to include caring for patients at the end of life stages of life is essential. Also, continuing education of nurses in Iran is necessary in order to their orientation with end of life care and hospice. Also, nurses' positive attitude toward providing hospice is a positive point in establishing hospice care in Iran.

This study has some limitations. There is no established end of life care in Iran and so, the awareness and familiarity of nurses regarding end of life care was investigated. Also, this study has been conducted in one province of Iran and does not cover the entire cultural and ethnitic background of Iran. So it is recommended that similar studies in this regard to be conducted in other regions of the country. Also, the actual knowledge of Iran nurses in this regarded should be investigated.
Considering the weak awareness of participants of present study, designing and implementing courses and scientific seminars regarding end of life care especially in the context of hospice care is necessary for Iranian nurses. Especially considering the positive attitude of nurses regarding end of life care is essential in implementing such programs.

\section{Acknowledgements}

We extremely appreciate and thank to all nurses who accepted to participate in present study. This article is based on the results of MS thesis at Tabriz nursing and midwifery faculty.

\section{References}

AAbu Hasheesh MO, Al-Sayed AboZeid S, El-Said SG, Alhujaili AD (2013). Nurses' characteristics and their attitudes toward death and caring for dying patients in a public hospital in jordan. Health Sci J, 7, 384-94.

Alexandria V (2013). National hospice and palliative care association:hospice care in America. NHPCO facts and figures.

Almuzaini A, Nicholls P, Alomar B (1998). The attitude of health care professionals toward the availability of hospice services for cancer patients and their carers in Saudi Arabia. Palliative Med, 12, 365-73.

Azami Aghdash S, Ghojazadeh M, Naghavi M, Imani S, Aghaei A (2015). Perspectives of Cardiac Care Unit Nursing Staff about Developing Hospice Services in Iran for Terminally ill Cardiovascular Patients: A Qualitative Study. Indian J Palliative Care, 21, 56-60.

Baghaei P, Zandi M, Vares Z, Masoodialavi N, Adibhajbagheri M (2008). Self-care behaviour of patients with diabetes in Kashan centers of diabetes. Quarterly J Feiz, 12, 88-93.

Carol T, Carol L, Priscilla L (2008). Fundamentals of nursing: the art science of nursing care, $5^{\text {ed }}$, Hayyan, 30-35.

Catherine W, Luker K (2010). District nurses' role in palliative care provision: A realist review. Int J Nurs Studies, 47, 167-83.

Cramer L, McCorkle R, Cherlin E, Jonson-Hurzeler R, Brandly E (2003). Nurses attitudes and practice related to hospice care. J Nurs Scholarship, 35, 249-55.

Csikos A, Mastrojohn J, Albanese T, et al (2010). Physicians beliefs and attitudes about end-of-life care:a comparison of selected regionns in hungary and the united states. $J$ Pain Symptom Manage, 39, 76-87.

David A, CHristopher P, Robert V, Denis J, John S (1993). Knowledge and perceptions of a domiciliary hospice service among general practitioners and community nurses. British J General Pract, 43, 57-9.

Dunn KS, Otten C, Stephens E (2005). Nursing experience and the care of dying patients. Oncol Nurs Forum, 32, 97-104.

Fink R, Gates R (2010). Pain assessment. Oxford Textbook of Palliative Nursing, $3^{\text {ed }}$, Oxford University Press.

Hauptman P, Havranek E (2005). Choosing the heart failure patient appropriate for palliative care. Arch Int Med, 165, 374-8.

Khan NF, Ward A, Watson E, Austoker J, Rose PW (2008). Longterm survivors of adult cancers and uptake of primary health services: a systematic review. Euro J Cancer, 44, 195-204.

Kirchhoff AC, Yi J, Wright J, Warner EL, Smith KR (2012). Marriage and divorce among young adult cancer survivors. J Cancer Surviv, 6, 441-50.

Luminita D, Wim JA, Marinela V (2006). Experiences, 
knowledge, and opinions on palliative care among romanian general practitioners. Croat Med J, 47, 142-7.

Magantoa V, Gonzálezb M, Morenoa M (2004). Continuous care in the cancer patient: palliative care in the $21^{\text {st }}$ century. Rev Oncol, 6, 448-57.

National Hospice and Palliative Care Organisation (2010). http:// www.caringinfo. org/LivingWithAnIllness/PalliativeCare. htm.

National Hospice Foundation (2012). What is hospice? Retrieved February 4, 2012, from http://www.hospiceinfo.org.

Ogle K, Mavis B, Wang T (2003). Hospice and primary care physicians: attitudes, knowledge and barriers. Am J Hosp Palliat Care, 20, 41-51.

Park SA, Chung SH, Shin EH (2012). Attitudes of nurses toward supportive care for advanced cancer patients. Asian Pac J Cancer Prev, 13, 4953-8.

Sharifa Ezat WP, Fuad I, Hayati Y, Zafar A, Wanda Kiyah GA (2014). Observational study on patient's satisfactions and quality of life (QoL) among cancer patients receiving treatment with palliative care intent in a tertiary hospital in Malaysia. Asian Pac J Cancer Prev, 15, 695-701.

Sharon A, Michael G, Ann R, Mary A (2006). Knowledge of rural nurses' aides about end-of-life care. Fam Community Health, 29, 229-41.

Stephan C, Emily H, Jane C (2008). Nurses perceptions of hospice palliative care volunteers. Am J Hospice Palliative Med, 25, 169-78.

Torben B, Martin S, Nils S (2009). Palliative care for older people - exploring the views of doctors and nurses from different fields in Germany. BMC Palliative Care, 8, 51-62.

World Health Organization (2002). National cancer control programmes: policies and managerial guidelines. ( $\left.2^{\text {nd }} \mathrm{edn}\right)$. World Health Organization: Geneva. 